\title{
Association between the methylation status of the MGMT promoter in bone marrow specimens and chemotherapy outcomes of patients with acute myeloid leukemia
}

\author{
QINGXIAO HONG $^{1 *}$, XIAOYING CHEN $^{1 *}$, HUADAN YE $^{1}$, ANNAN ZHOU $^{1}$, \\ YUTING GAO $^{1}$, DANJIE JIANG ${ }^{1}$, XIAODONG WU ${ }^{2}$, BINGRU TIAN ${ }^{2}$, YOUFEN CHEN ${ }^{2}$, \\ MING WANG $^{2}$, JIPING XIE ${ }^{2}$, YONGMING XIA ${ }^{2}$ and SHIWEI DUAN ${ }^{1}$ \\ ${ }^{1}$ Department of Biochemistry and Molecular Biology, \\ Zhejiang Provincial Key Laboratory of Pathophysiology, School of Medicine, Ningbo University, Ningbo, \\ Zhejiang 315211; ${ }^{2}$ Department of Hematology, Yuyao People's Hospital, Yuyao, Zhejiang 315400, P.R. China \\ Received January 6, 2015; Accepted February 4, 2016
}

DOI: $10.3892 / 01.2016 .4317$

\begin{abstract}
The $O(6)$-methylguanine-DNA methyltransferase $(M G M T)$ gene is a tumor suppressor gene that is associated with the risk of developing acute myeloid leukemia (AML). However, the association between the methylation status of the MGMT promoter and the chemotherapeutic outcomes of patients with AML remains unknown. In the present study, 30 bone marrow samples derived from patients with AML were collected prior and subsequent to chemotherapy. The methylation status of the $M G M T$ promoter in the bone marrow specimens was determined by methylation-specific polymerase chain reaction. The results indicated that the methylation status of the MGMT promoter was influenced by different chemotherapeutic regimens. The $M G M T$ methylation status of M4 patients ( 3 out of 6 ) were more chemosensitive, compared with that of patients with other AML subtypes (M1, 1 out of 3; M2, 0 out of 8; M3, 3 out of 7; M5, 0 out of 3; and M6, 1 out of 3). Age-based analysis revealed that the group aged $\leq 60$ years (7 out of 24 patients) exhibited more methylation changes than patients aged $>60$ years ( 1 out of 6 ). Male patients ( 4 out of 13 ) were more susceptible to chemotherapy-induced methylation changes than female patients (4 out of 17). Thus, the methylation status of the $M G M T$ promoter may serve as a potential
\end{abstract}

Correspondence to: Professor Shiwei Duan, Department of Biochemistry and Molecular Biology, Zhejiang Provincial Key Laboratory of Pathophysiology, School of Medicine, Ningbo University, 818 Fenghua Road, Ningbo, Zhejiang 315211, P.R. China E-mail: duanshiwei@nbu.edu.cn

Dr Yongming Xia, Department of Hematology, Yuyao People's Hospital, 800 Chengdong Road, Yuyao, Zhejiang 315400, P.R. China E-mail:xymfll@163.com

*Contributed equally

Key words: acute myeloid leukemia, chemotherapy, promoter, methylation, $M G M T$ biomarker to predict the therapeutic outcomes in male AML patients. However, further studies in larger sample sets are required to confirm the present findings.

\section{Introduction}

Acute myeloid leukemia (AML) is a highly heterogeneous hematologic malignancy, which is characterized by the rapid growth of abnormal white blood cells that accumulate in the peripheral blood, bone marrow and other tissues $(1,2)$. AML is the most common form of acute leukemia in adults (3), and is treated initially with chemotherapy with the aim of inducing a remission (4). Demethylation agents such as azacitidine and decitabine have been previously used in the treatment of AML (5). Aberrant $\mathrm{CpG}$ island hypermethylation of tumor suppressor genes has been shown to be important in inducing transcriptional silencing of genes in leukemic cells (6). Therefore, the promoter methylation status of cancer-associated genes may serve as a predictive and prognostic biomarker in the pathogenesis of various types of cancer (7).

The O(6)-methylguanine-DNA methyltransferase (MGMT) gene encodes a unique DNA repair enzyme that removes mutagenic and cytotoxic alkyl adducts from the $\mathrm{O}(6)$ position of guanine (8). Hypermethylation of the MGMT promoter was identified in certain tumor cell lines such as non-Hodgkin lymphoma and AML (9). Targeted therapy was feasible in patients with AML who displayed low expression levels of MGMT (10). However, the frequency of $M G M T$ promoter methylation in AML, and its potential prognostic value remain to be elucidated.

The aim of the present study was to evaluate whether the promoter methylation status of the MGMT gene would be influenced by chemotherapeutic agents, and whether the methylation changes induced by the treatment would be able to predict the chemotherapeutic outcomes of patients with AML.

\section{Materials and methods}

Samples. Bone marrow samples from 30 individuals with AML were collected by the members of the Department of 
Hematology of Yuyao People's Hospital (Ningbo, China) between January 2013 and June 2014. AML diagnosis was established in accordance with the revised French-American-British (FAB) classification (11). There were 13 male and 17 female AML patients, with a mean age of 47.8 \pm 15.4 years (range, 19-76 years). The present study was approved by the Ethics Committee of Yuyao People's Hospital, and all the donors signed the informed consent form for participation in the study.

DNA isolation and bisulfite conversion. Genomic DNA was extracted using a nucleic acid extraction automatic analyzer (Lab-Aid 820; Zeesan Biotech, Xiamen, China). DNA concentration was measured with NanoDrop 1000 spectrophotometer (Thermo Fisher Scientific, Inc., Wilmington, DE, USA). DNA samples were subjected to bisulfite conversion by EZ DNA Methylation-Gold ${ }^{\mathrm{TM}}$ kit (Zymo Research Corporation, Irvine, CA, USA), according to the manufacturer's protocol.

Methylation-specific polymerase chain reaction (MSP) and $D N A$ sequencing. The methylation status of the MGMT promoter was determined by MSP (12). The reaction contained $1.5 \mu \mathrm{l}$ sodium bisulfite-converted DNA, $0.5 \mu \mathrm{l}$ forward primer, $0.5 \mu 1$ reverse primer (13), $10 \mu 1 \mathrm{ZymoTaq}^{\mathrm{TM}}$ PreMix (Zymo Research Corporation) and 7.5 $\mu \mathrm{l}$ DNAase/RNAase-free water (Zymo Research Corporation), in a final volume of $20 \mu \mathrm{l}$. The details of the methylated and unmethylated primers used are provided in Table I. DNA amplification was performed on Veriti ${ }^{\circledR}$ PCR machine (Applied Biosystems, Thermo Fisher Scientific, Inc.), and the following amplification conditions were used: $95^{\circ} \mathrm{C}$ for $10 \mathrm{~min}$, followed by 30 or 35 cycles at $94^{\circ} \mathrm{C}$ for $30 \mathrm{sec}, 55^{\circ} \mathrm{C}$ for $45 \mathrm{sec}$ and $72^{\circ} \mathrm{C}$ for $1 \mathrm{~min}$. PCR products were subjected to the Qsep100 DNA Analyzer (BiOptic Inc., Taiwan, China). Samples were considered as methylated or unmethylated when peaks were clearly visible by Q-Analyzer software (BiOptic Inc.) (Fig. 1). A number of DNA samples were randomly sequenced using the 3730 DNA Analyzer (Applied Biosystems; Thermo Fisher Scientific, Inc.) to confirm a complete bisulfite conversion (Fig. 2).

Statistical analysis. Statistical analyses were performed using SPSS version 18.0 (SPSS, Inc., Chicago, IL, USA). MSP results were compared between prior and post-chemotherapy. A two-tailed P-value of $<0.05$ was considered to indicate a statistically significant difference.

\section{Results}

MSP analysis of bone marrow samples from AML patients. To determine whether the chemotherapy treatment would change the methylation status of the MGMT promoter in patients with AML, the pre- and post-chemotherapy bone marrow samples of 30 patients with AML were subjected to MSP analysis. The chemotherapy agents used to treat the patients, including cytarabine (Ara-C), idarubicin (IDA), arsenic trioxide $\left(\mathrm{As}_{2} \mathrm{O}_{3}\right)$, all-trans retinoic acid (ATRA), homoharringtonine (HHT), granulocyte-colony stimulating factor (G-CSF), aclacinomycin (ACLA) and daunorubicin (DNR), are described in Table II. The details of the chemotherapy regimens of all patients are presented in Table III.

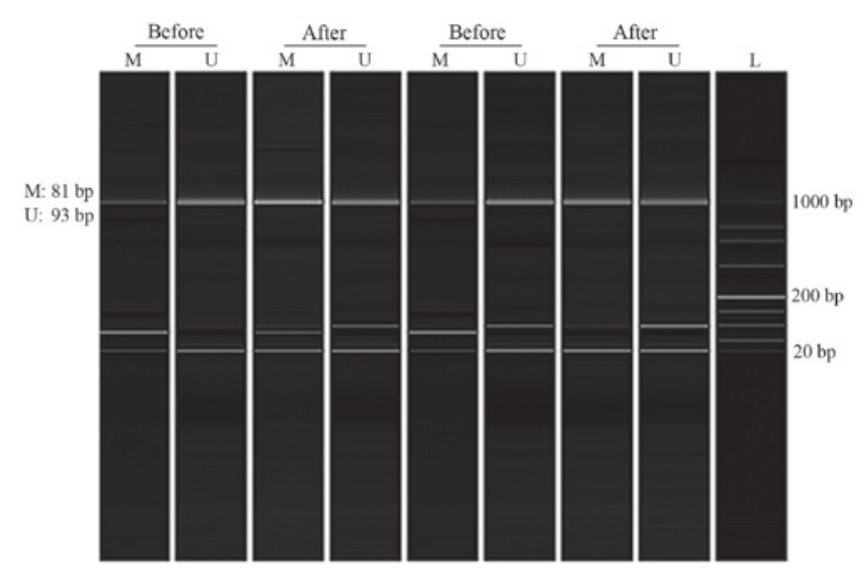

Figure 1. Methylation status of the $O(6)$-methylguanine-DNA methyltransferase gene in patients with acute myeloid leukemia prior or subsequent to chemotherapy, as analyzed by methylation-specific polymerase chain reaction using methylated or unmethylated primers. The methylated and unmethylated primer sets differentiate the methylation into full methylation $(\mathrm{M} /-)$, partial methylation $(\mathrm{M} / \mathrm{U})$ and unmethylated $(-/ \mathrm{U})$. Methylated; $\mathrm{U}$, unmethylated; L, DNA ladders.

Regimen-based subgroup analysis of methylation changes in patients with AML. A total of 8 patients subjected to 6 different chemotherapy regimens presented chemotherapy-induced methylation changes, including 1 patient with induced hypermethylation and 7 patients with induced hypomethylation. Among the 3 patients under IDA+Ara-C treatment, 1 exhibited induced hypermethylation and poor prognosis, in contrast to the other 2 patients, who exhibited induced hypomethylation and poor prognosis. The remaining 5 patients with induced hypomethylation and good prognosis were under ATRA+As $\mathrm{O}_{3}$, $\mathrm{IDA}+\mathrm{Ara}-\mathrm{C}+\mathrm{ACLA}+\mathrm{G}-\mathrm{CSF}+\mathrm{HHT}, \mathrm{HHT}+\mathrm{Ara}-\mathrm{C}+\mathrm{G}-\mathrm{CSF}$, ATRA $+\mathrm{As}_{2} \mathrm{O}_{3}+\mathrm{HHT}+\mathrm{Ara}-\mathrm{C}$ and $\mathrm{HHT}+\mathrm{Ara}-\mathrm{C}+\mathrm{ACLA}$ treatment, respectively.

AML subtype-based subgroup analysis of methylation changes in patients with AML. The present cohort included $3 \mathrm{M} 1,8 \mathrm{M} 2$, 7 M3, 6 M4, 3 M5 and 3 M6 AML subtypes. The outcomes of chemotherapy-induced methylation changes differed among the various AML subtypes. Chemotherapy-induced methylation changes were more frequent among M4 subtype patients (50.0\%, 3 out of 6 patients), compared with other subtypes (M1, $33.3 \%, 1$ out of 3 patients; M2, $0.0 \%, 0$ out of 8 patients; M3, $42.9 \%, 3$ out of 7 patients; M5, $0.0 \%, 0$ out of 3 patients; and M6, $33.3 \%, 1$ out of 3 patients). Of the aforementioned M4 cases, 2 patients who had received IDA+Ara-C+ACLA+G-CSF+HHT and HHT+Ara-C+ACLA treatment, respectively, presented chemotherapy-induced hypomethylation and good prognosis, whereas 1 patient who had been treated with IDA+Ara-C exhibited chemotherapy-induced hypomethylation and poor prognosis.

Age-based subgroup analysis of methylation changes in patients with AML. In the present study, there were $24 \mathrm{AML}$ patients aged $\leq 60$ years and 6 AML patients aged $>60$ years. Analysis by age revealed that chemotherapy-induced methylation changes were more often observed among AML patients aged $\leq 60$ years $(29.2 \%, 7$ out of 24 patients), compared with those aged $>60$ years $(16.7 \%, 1$ out of 6 patients). Among 
Table I. List of all primers and conditions used in polymerase chain reaction amplification.

\begin{tabular}{|c|c|c|c|c|}
\hline Primer set & Primer sequence, $5^{\prime}-3^{\prime}$ & Target size, bp & $\mathrm{Ta},{ }^{\circ} \mathrm{C}$ & Cycles, no. \\
\hline Methylated & & 81 & 55 & 35 \\
\hline $\mathrm{F}$ & TTTCGACGTTCGTAGGTTTTCGC & & & \\
\hline $\mathrm{R}$ & GCACTCTTCCGAAAACGAAACG & & & \\
\hline Unmethylated & & 93 & 55 & 30 \\
\hline $\mathrm{F}$ & TTTGTGTTTTGATGTTTGTAGGTTTTTGT & & & \\
\hline $\mathrm{R}$ & ААСТССАСАСТСТТССАААААСААААСА & & & \\
\hline
\end{tabular}

F, forward; R, reverse; Ta, annealing temperature.

A
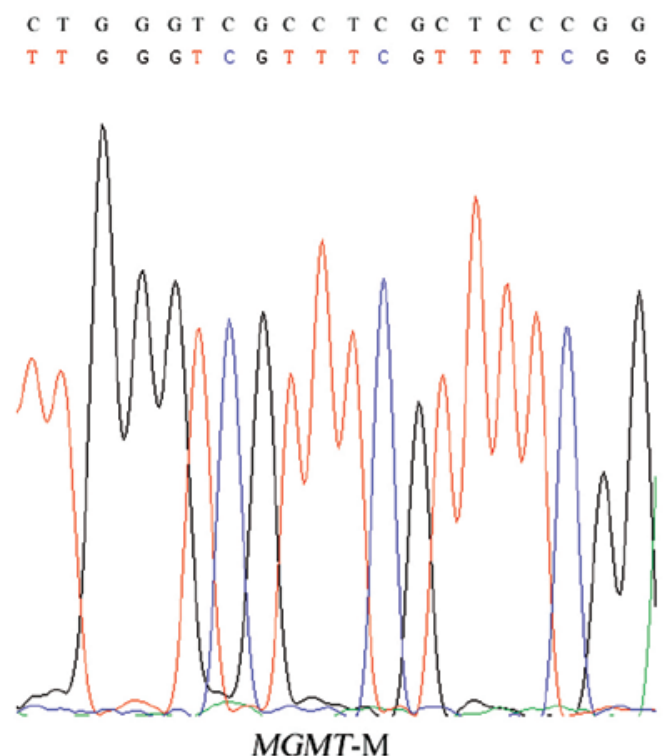

B
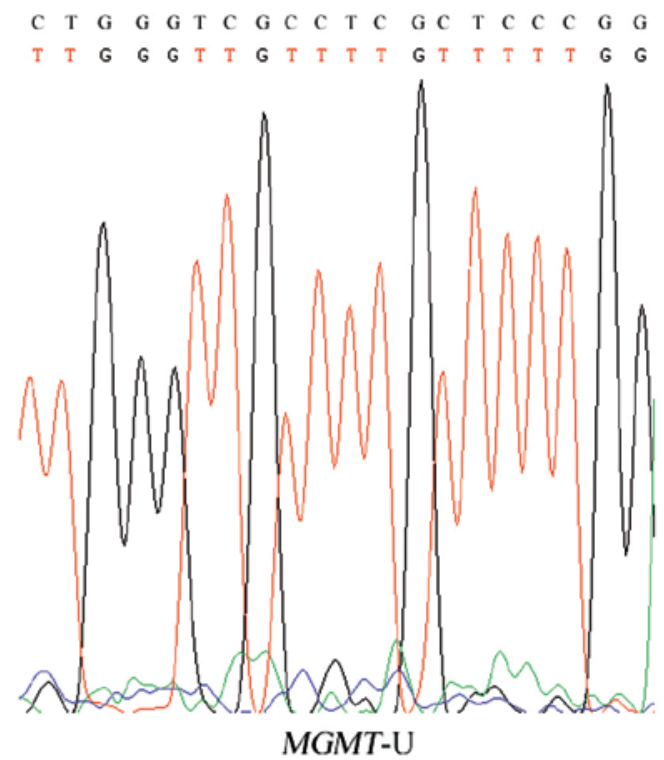

Figure 2. Validation of the results obtained by methylation-specific polymerase chain reaction via DNA sequencing. Representative images of (A) methylated and (B) unmethylated $O(6)$-methylguanine-DNA methyltransferase gene. MGMT, O(6)-methylguanine-DNA methyltransferase; M, methylated; U, unmethylated.

the patients aged $\leq 60$ years, $1 \mathrm{M} 1$ patient (IDA+Ara-C, aged 49 years) exhibited chemotherapy-induced hypermethylation and poor prognosis; $2 \mathrm{M} 3$ patients $\left(\mathrm{ATRA}+\mathrm{As}_{2} \mathrm{O}_{3}\right.$, aged 23 years; and ATRA+As $\mathrm{O}_{3}+\mathrm{HHT}+\mathrm{Ara}-\mathrm{C}$, aged 51 years) presented chemotherapy-induced hypomethylation and remission; 1 M3 patient (aged 42 years) experienced worsening of the condition following IDA+Ara-C treatment; 1 M4 patient (IDA+Ara-C, aged 30 years) exhibited chemotherapy-induced hypomethylation and aggravation of the condition; 1 M4 patient (HHT+Ara-C+ACLA, aged 19 years) displayed chemotherapy-induced hypomethylation along with remission; and 1 M6 patient (HHT+Ara-C+G-CSF, aged 52 years) presented chemotherapy-induced hypomethylation along with remission. Only $1 \mathrm{M} 4$ patient aged $>60$ years (IDA+Ara-C+ACLA+G-CSF+HHT, aged 67 years) exhibited chemotherapy-induced hypomethylation and remission.

Gender-based subgroup analysis of methylation changes in patients with $A M L$. In total, 4 out of 13 male patients and 4 out of 17 female patients who had been subjected to different combined regimens exhibited chemotherapy-induced methylation changes in the promoter of the MGMT gene. Among the male patients, 1 M1 patient (IDA+Ara-C) presented hypermethylation along with poor prognosis, whereas $1 \mathrm{M} 3$ patient $\left(\mathrm{ATR} A+\mathrm{As}_{2} \mathrm{O}_{3}\right), 1 \mathrm{M} 4$ patient (IDA+Ara-C+ACLA+G-CSF+HHT) and 1 M6 patient (HHT+Ara-C+G-CSF) presented chemotherapy-induced hypomethylation along with remission. The remaining 9 male patients ( 2 of which had been treated with HHT+Ara-C+ACLA, 1 with HHT+Ara-C, 1 with Ara-C+ACLA+G-CSF, 1 with IDA+Ara-C, 1 with $\mathrm{As}_{2} \mathrm{O}_{3}+\mathrm{DNR}+\mathrm{ATRA}, 1$ with Ara-C and 1 with Ara-C+ACLA) did not exhibit any methylation changes induced by the chemotherapeutic agents.

In the female subgroup, $1 \mathrm{M} 3$ patient who had been treated with ATRA+As $\mathrm{O}_{3}+\mathrm{HHT}+\mathrm{Ara}-\mathrm{C}$ ) and $1 \mathrm{M} 4$ patient who had been treated with HHT+Ara-C+ACLA presented chemotherapy-induced hypomethylation along with good prognosis, while 2 female patients (1 M3 and 1 M4 who had been treated with IDA+Ara-C) exhibited chemotherapy-induced hypomethylation and poor prognosis. The remaining 13 female patients (4 of which had been treated with Ara-C, 3 with Ara-C+ACLA+G-CSF, 2 with HHT+Ara-C, 2 with 
Table II. Clinical parameters of patients with acute myeloid leukemia.

\begin{tabular}{|c|c|c|c|c|c|c|}
\hline Case & Gender & Age, years & Subtype & Chemotherapy regimen & Remission & Methylation level \\
\hline 1 & Male & 55 & M1 & $\mathrm{HHT}+\mathrm{Ara}-\mathrm{C}+\mathrm{ACLA}$ & Yes & $\mathrm{M} / \mathrm{U}$ to $\mathrm{M} / \mathrm{U}$ \\
\hline 2 & Male & 49 & M1 & $\mathrm{IDA}+\mathrm{Ara}-\mathrm{C}$ & No & $\mathrm{M} / \mathrm{U}$ to $\mathrm{M}$ \\
\hline 3 & Male & 76 & M2 & $\mathrm{Ara}-\mathrm{C}+\mathrm{ACLA}+\mathrm{G}-\mathrm{CSF}$ & No & $\mathrm{M} / \mathrm{U}$ to $\mathrm{M} / \mathrm{U}$ \\
\hline 4 & Male & 66 & M2 & $\mathrm{IDA}+\mathrm{Ara}-\mathrm{C}$ & Yes & $\mathrm{M} / \mathrm{U}$ to $\mathrm{M} / \mathrm{U}$ \\
\hline 5 & Male & 23 & M3 & $\mathrm{ATRA}+\mathrm{As}_{2} \mathrm{O}_{3}$ & Yes & $\mathrm{M}$ to $\mathrm{M} / \mathrm{U}$ \\
\hline 6 & Male & 40 & M3 & $\mathrm{As}_{2} \mathrm{O}_{3}+\mathrm{DNR}+\mathrm{ATRA}$ & No & $\mathrm{M}$ to $\mathrm{M}$ \\
\hline 7 & Male & 59 & M3 & $\mathrm{HHT}+\mathrm{Ara}-\mathrm{C}$ & Yes & $\mathrm{M}$ to $\mathrm{M}$ \\
\hline 8 & Male & 67 & M4 & $\mathrm{IDA}+\mathrm{Ara}-\mathrm{C}+\mathrm{ACLA}+\mathrm{G}-\mathrm{CSF}+\mathrm{HHT}$ & Yes & $\mathrm{M} / \mathrm{U}$ to $\mathrm{U}$ \\
\hline 9 & Male & 34 & M4 & $\mathrm{HHT}+\mathrm{Ara}-\mathrm{C}$ & Yes & $\mathrm{M} / \mathrm{U}$ to $\mathrm{M} / \mathrm{U}$ \\
\hline 10 & Male & 68 & M5 & Ara-C & Yes & $\mathrm{M} / \mathrm{U}$ to $\mathrm{M} / \mathrm{U}$ \\
\hline 11 & Male & 59 & M5 & Ara-C+ACLA & Yes & $\mathrm{M} / \mathrm{U}$ to $\mathrm{M} / \mathrm{U}$ \\
\hline 12 & Male & 48 & M5 & $\mathrm{HHT}+\mathrm{Ara}-\mathrm{C}+\mathrm{ACLA}$ & No & $\mathrm{M} / \mathrm{U}$ to $\mathrm{M} / \mathrm{U}$ \\
\hline 13 & Male & 52 & M6 & $\mathrm{HHT}+\mathrm{Ara}-\mathrm{C}+\mathrm{G}-\mathrm{CSF}$ & Yes & $\mathrm{M}$ to $\mathrm{M} / \mathrm{U}$ \\
\hline 14 & Female & 59 & M1 & Ara-C+ACLA+G-CSF & No & $\mathrm{M} / \mathrm{U}$ to $\mathrm{M} / \mathrm{U}$ \\
\hline 15 & Female & 66 & M2 & Ara-C+ACLA+G-CSF & Yes & $\mathrm{M} / \mathrm{U}$ to $\mathrm{M} / \mathrm{U}$ \\
\hline 16 & Female & 56 & M2 & Ara-C+ACLA+G-CSF & Yes & $\mathrm{M} / \mathrm{U}$ to $\mathrm{M} / \mathrm{U}$ \\
\hline 17 & Female & 48 & M2 & HHT+Ara-C+ACLA & Yes & $\mathrm{M} / \mathrm{U}$ to $\mathrm{M} / \mathrm{U}$ \\
\hline 18 & Female & 50 & M2 & $\mathrm{HHT}+\mathrm{Ara}-\mathrm{C}+\mathrm{G}-\mathrm{CSF}+\mathrm{IDA}$ & Yes & $\mathrm{M} / \mathrm{U}$ to $\mathrm{M} / \mathrm{U}$ \\
\hline 19 & Female & 19 & M2 & $\mathrm{HHT}+\mathrm{Ara}-\mathrm{C}+\mathrm{ACLA}$ & Yes & $\mathrm{M} / \mathrm{U}$ to $\mathrm{M} / \mathrm{U}$ \\
\hline 20 & Female & 53 & M2 & $\mathrm{HHT}+\mathrm{Ara}-\mathrm{C}$ & Yes & $\mathrm{M} / \mathrm{U}$ to $\mathrm{M} / \mathrm{U}$ \\
\hline 21 & Female & 51 & M3 & $\mathrm{ATRA}+\mathrm{As}_{2} \mathrm{O}_{3}+\mathrm{HHT}+\mathrm{Ara}-\mathrm{C}$ & Yes & $\mathrm{M}$ to $\mathrm{M} / \mathrm{U}$ \\
\hline 22 & Female & 42 & M3 & $\mathrm{IDA}+\mathrm{Ara}-\mathrm{C}$ & No & $\mathrm{M}$ to $\mathrm{M} / \mathrm{U}$ \\
\hline 23 & Female & 30 & M3 & Ara-C & Yes & $\mathrm{M} / \mathrm{U}$ to $\mathrm{M} / \mathrm{U}$ \\
\hline 24 & Female & 31 & M3 & Ara-C & Yes & $\mathrm{M} / \mathrm{U}$ to $\mathrm{M} / \mathrm{U}$ \\
\hline 25 & Female & 30 & M4 & IDA & Yes & $\mathrm{M} / \mathrm{U}$ to $\mathrm{M} / \mathrm{U}$ \\
\hline 26 & Female & 30 & M4 & $\mathrm{IDA}+\mathrm{Ara}-\mathrm{C}$ & No & $\mathrm{M}$ to $\mathrm{M} / \mathrm{U}$ \\
\hline 27 & Female & 19 & M4 & $\mathrm{HHT}+\mathrm{Ara}-\mathrm{C}+\mathrm{ACLA}$ & Yes & $\mathrm{M}$ to $\mathrm{M} / \mathrm{U}$ \\
\hline 28 & Female & 42 & M4 & Ara-C & Yes & $\mathrm{M} / \mathrm{U}$ to $\mathrm{M} / \mathrm{U}$ \\
\hline 29 & Female & 64 & M6 & $\mathrm{HHT}+\mathrm{Ara}-\mathrm{C}$ & No & $\mathrm{M} / \mathrm{U}$ to $\mathrm{M} / \mathrm{U}$ \\
\hline 30 & Female & 50 & M6 & Ara-C & Yes & $\mathrm{M} / \mathrm{U}$ to $\mathrm{M} / \mathrm{U}$ \\
\hline
\end{tabular}

M, full methylation; M/U, partial methylation; U, unmethylation; Ara-C, cytarabine; IDA, idarubicin; $\mathrm{As}_{2} \mathrm{O}_{3}$, arsenic trioxide; ATRA, all-trans retinoic acid; HHT, homoharringtonine; G-CSF, granulocyte-colony stimulating factor; ACLA, aclacinomycin; DNR, daunorubicin.

Ara-C+ACLA+G-CSF, 1 with $\mathrm{HHT}+\mathrm{Ara}-\mathrm{C}+\mathrm{G}-\mathrm{CSF}+\mathrm{IDA}$ and 1 with IDA) did not exhibit any induced methylation changes following chemotherapy.

\section{Discussion}

Increasing evidence has demonstrated that epigenetics, including DNA methylation, is important in the pathogenesis of cancer (14). The dysregulation of critical genes involved in cell growth, differentiation, apoptosis and repair of DNA lesions may increase the incidence of malignant phenotypes (15). As a DNA repair enzyme, MGMT mainly participates in maintaining genomic stability if spontaneous mutagenesis occurs (10). However, the association between chemotherapy-induced methylation changes in the $M G M T$ promoter and pathogenesis of AML has not been fully elucidated thus far. The aim of the present study was to explore the association between the chemotherapeutic outcomes of patients with AML and the chemotherapy-induced methylation changes in the promoter of the MGMT gene that occur in the bone marrow of AML patients during chemotherapeutic treatment.

The results of the present study demonstrated that the methylation status of the $M G M T$ promoter changed during the treatment with different chemotherapeutic regimens. MGMT was observed to be more often hypomethylated (7 patients out of 8) than hypermethylated (1 patient out of 8 ) by the different chemotherapeutic regimens. Among the AML patients, M4 (3 out of 6 patients) and M3 patients (3 out of 7 patients) exhibited chemotherapy-induced methylation changes more frequently than patients with other AML subtypes. Age-based subgroup analysis revealed that patients aged $\leq 60$ years ( 7 out of 24 patients) presented methylation changes more frequently than patients aged $>60$ years $(1$ out of 6 patients). In addition, male patients appeared to be more susceptible to chemotherapy-induced methylation changes than female patients. 
Table III. Details of the chemotherapy regimens of all the acute myeloid leukemia patients.

\begin{tabular}{|c|c|}
\hline Case & Chemotherapy regimen, dose, treatment duration (route of administration, frequency) \\
\hline 1 & HHT: 3 mg, D1-D5 (ivgtt, qd); Ara-C: 75 mg, D1-D5 (ih, q12h); ACLA: 20 mg, D1-D5 (ivgtt, qd) \\
\hline 2 & IDA: 15 mg, D1-D3 (ivgtt, qd); Ara-C: 100 mg, D1-D5 (ih, q12h) \\
\hline 3 & Ara-C: 15 mg, D1-D14 (ih, q12h); ACLA: 10 mg, D1-D4 (ivgtt, qod); G-CSF: $200 \mu \mathrm{g}$ (ih, q12h) \\
\hline 4 & IDA: 10 mg, D1-D3 (ivgtt, qd); Ara-C: 75 mg, D1-D7 (ih, q12h) \\
\hline 5 & ATRA: 10 mg, D1-D14 (po, tid); $\mathrm{As}_{2} \mathrm{O}_{3}: 10 \mathrm{mg}, \mathrm{D} 1-\mathrm{D} 14$ (ivgtt, qod) \\
\hline 6 & $\mathrm{As}_{2} \mathrm{O}_{3}: 9$ mg, D1-D14 (ivgtt, qd); DNR: 60 mg, D1-D3 (ivgtt, qd); ATRA: 10 mg, D1-D14 (po, bid) \\
\hline 7 & HHT: 3.8 mg, D1-D7 (ivgtt, qd); Ara-C: 95 mg, D1-D5 (ih, q12h) \\
\hline 8 & $\begin{array}{l}\text { IDA: } 10 \text { mg, D1-D2 (ivgtt, qd); Ara-C: } 75 \text { mg, D1-D3 (ih, q12h); ACLA: } 10 \text { mg, D1-D5 (ivgtt, qod); } \\
\text { G-CSF: } 300 \mu \mathrm{g} \text { (ih, qd); HHT: } 2 \text { mg, D1-D5 (ivgtt, qd) }\end{array}$ \\
\hline 9 & HHT: 2 mg, D1-D5 (ivgtt, qd); Ara-C: 100 mg, D1-D5 (ih, q12h) \\
\hline 10 & Ara-C: 22.5 mg, D1-D3 (ih, q12h) \\
\hline 11 & Ara-C: 100 mg, D1-D5 (ih, q12h); ACLA: 100 mg, D1-D5 (ivgtt, qod) \\
\hline 12 & HHT: 2 mg, D1-D3 (ivgtt, qd); Ara-C: 100 mg, D1-D3 (ih, q12h); ACLA: 100 mg, D1-D3 (ivgtt, qod) \\
\hline 13 & HHT: 2 mg, D1-D5 (ivgtt, qd); Ara-C: 100 mg, D1-D5 (ih, q12h); G-CSF $400 \mu \mathrm{g}$ (ih, qd) \\
\hline 14 & Ara-C: 16 mg, D1-D14 (ih, q12h); ACLA: 20 mg, D1-D4 (ivgtt, qod); G-CSF: $300 \mu \mathrm{g}$ (ih, qd) \\
\hline 15 & Ara-C: 15 mg, D1-D14 (ih, q12h); ACLA: 20 mg, D1-D7 (ivgtt, qod); G-CSF: $300 \mu \mathrm{g}$ (ih, qd) \\
\hline 16 & Ara-C: 16 mg, D1-D14 (ih, q12h); ACLA: 20 mg, D1-D4 (ivgtt, qod); G-CSF: $300 \mu \mathrm{g}$ (ih, qd) \\
\hline 17 & HHT: 2.8 mg, D1-D5 (ivgtt, qd); Ara-C: 70 mg, D1-D7 (ih, q12h); ACLA: 20 mg, D1-D5 (ivgtt, qd) \\
\hline 18 & $\begin{array}{l}\text { HHT: } 3 \text { mg, D1-D7 (ivgtt, qd); Ara-C: } 15 \text { mg, D1-D14 (ih, q12h); G-CSF: } 200 \text { mg (ih, qd); } \\
\text { IDA: } 10 \text { mg, D1-D4 (ivgtt, qd) }\end{array}$ \\
\hline 19 & HHT: 3 mg, D1-D5 (ivgtt, qd); Ara-C: 75 mg, D1-D5 (ih, q12h); ACLA: 20 mg, D1-D5 (ivgtt, qd) \\
\hline 20 & HHT: 2 mg, D1-D5 (ivgtt, qd); Ara-C: 100 mg, D1-D5 (ih, q12h) \\
\hline 21 & $\begin{array}{l}\text { ATRA: } 20 \mathrm{mg}, \mathrm{D} 1-\mathrm{D} 14 \text { (po, bid); } \mathrm{As}_{2} \mathrm{O}_{3}: 10 \mathrm{mg} \text {, D1-D14 (ivgtt, qd); HHT: } 3 \text { mg, D1-D5 (ivgtt, qd); } \\
\text { Ara-C: } 15 \mathrm{mg} \text {, D1-D5 (ivgtt, qd) }\end{array}$ \\
\hline 22 & IDA: 10 mg, D1-D3 (ivgtt, qd); Ara-C: 146 mg, D1-D5 (ih, q12h) \\
\hline 23 & Ara-C: 12.5 mg, D1-D3 (ih, q12h) \\
\hline 24 & Ara-C: 100 mg, D1-D3 (ih, q12h); \\
\hline 25 & IDA: 15 mg, D1-D3 (ivgtt, qd) \\
\hline 26 & IDA: 15 mg, D1-D3 (ivgtt, qd); Ara-C: 400 mg, D1-D7 (ih, q12h) \\
\hline
\end{tabular}

HHT, homoharringtonine; D, day; ivgtt, intravenous drip; qd, administered once per day; Ara-C, cytarabine; ih, hypodermic injection; q12h, administered once every 12 hours; ACLA, aclacinomycin; IDA, idarubicin; qod, administered once every other day; G-CSF, granulocyte-colony stimulating factor; ATRA, all-trans retinoic acid; po, oral; tid, three times a day; $\mathrm{As}_{2} \mathrm{O}_{3}$, arsenic trioxide; DNR, daunorubicin; bid, administered twice per day.

Different subtypes of AML may exhibit different responses to multiple chemotherapeutics, which may influence DNA methylation and remission (16). According to the FAB classification, M3 is the best curable subtype of AML, due to its sensitivity toward ATRA treatment, which causes the differentiation of promyelocytes (17). The present findings revealed 3 hypomethylated patients, of which, 2 (who had been treated with ATRA+As $\mathrm{O}_{3}$ and ATRA $+\mathrm{As}_{2} \mathrm{O}_{3}+\mathrm{HHT}+\mathrm{Ara}-\mathrm{C}$, respectively) experienced emission, while 1 (wo had been subjected to IDA+Ara-C treatment) experienced aggravation of the condition, suggesting individual differences during chemotherapy. In addition, M4 patients presented chemotherapy-induced methylation changes more often than other subtypes, which suggests that the association between the methylation status of the $M G M T$ promoter and the chemotherapeutic outcomes of patients with AML may depend on the AML subtype.

Age may be an important risk factor in the selection of therapy for AML (18). Decreased visceral function, drug resistance and poor reactivity among the elders may lead to poor prognosis and high recurrence rate, which results in a poor overall 5-year survival rate for elderly AML patients (3). The analysis by age conducted in the present study demonstrated that chemotherapy-induced hypomethylation events were more frequent among AML patients aged $\leq 60$ years than among those aged $>60$ years, suggesting that young patients may be more sensitive to chemotherapeutic drugs.

Gender discrepancy must be considered when referring to cancer prognosis (19). A previous study emphasized the significantly higher incidence rates of acute leukemia in male patients, compared with female patients (20). In the present study, chemotherapy-induced hypomethylation of $M G M T$ along with good prognosis occurred more often in males than in females, suggesting the potential of this gene to serve as a biomarker to predict the chemotherapeutic outcomes in male patients with AML. Furthermore, IDA+Ara-C regimen led to worse outcomes among female patients, compared with males. 
In conclusion, the outcomes of chemotherapy-induced methylation of the $M G M T$ gene in AML patients varied among the different AML subtypes, gender and age of patients in the present study. MGMT promoter methylation may serve as a prognostic value for individualized chemotherapy in the future. However, further studies in larger sample sets are required to confirm the present findings.

\section{Acknowledgements}

The present study was supported by grants from the National Natural Science Foundation of China (Beijing, China; grant nos. 31100919 and 81371469), Zhejiang Provincial Natural Science Foundation (Hangzhou, China; grant no. LR13H020003), Ningbo City Medical Science and Technology Projects (Ningbo, China; grant no. 2014A20) and K. C. Wong Magna Fund in Ningbo University, Ningbo, China.

\section{References}

1. Estey EH: Acute myeloid leukemia: 2013 update on risk-stratification and management. Am J Hematol 88: 318-327, 2013.

2. Davis AS, Viera AJ and Mead MD: Leukemia: An overview for primary care. Am Fam Physician 89: 731-738, 2014.

3. Thein MS, Ershler WB, Jemal A, Yates JW and Baer MR: Outcome of older patients with acute myeloid leukemia: An analysis of SEER data over 3 decades. Cancer 119: 2720-2727, 2013.

4. Stringaris K, Sekine T, Khoder A, Alsuliman A, Razzaghi B, Sargeant R, Pavlu J, Brisley G, de Lavallade H, Sarvaria A, et al: Leukemia-induced phenotypic and functional defects in natural killer cells predict failure to achieve remission in acute myeloid leukemia. Haematologica 99: 836-847, 2014.

5. MaurilloL, Venditti A, Spagnoli A, Gaidano G, Ferrero D, Oliva E, Lunghi M, D'Arco AM, Levis A, Pastore D, et al: Azacitidine for the treatment of patients with acute myeloid leukemia: Report of 82 patients enrolled in an Italian Compassionate Program. Cancer 118: 1014-1022, 2012

6. Boultwood J and Wainscoat JS: Gene silencing by DNA methylation in haematological malignancies. Br J Haematol 138: 3-11, 2007.

7. Tuominen R, Jewell R, van den Oord JJ, Wolter P, Stierner U, Lindholm C, Hertzman Johansson C, Lindén D, Johansson H, Frostvik Stolt M, et al: MGMT promoter methylation is associated with temozolomide response and prolonged progression-free survival in disseminated cutaneous melanoma. Int J Cancer 136 : 2844-2853, 2015.
8. Iyama T and Wilson DM 3rd: DNA repair mechanisms in dividing and non-dividing cells. DNA Repair (Amst) 12: 620-636, 2013.

9. Kraguljac Kurtović N, Krajnović M, Bogdanović A, Suvajdžić N, Jovanović J, Dimitrijević B, Colović M and Krtolica K: Concomitant aberrant methylation of p15 and MGMT genes in acute myeloid leukemia: Association with a particular immunophenotype of blast cells. Med Oncol 29: 3547-3556, 2012.

10. Brandwein JM, Kassis J, Leber B, Hogge D, Howson-Jan K, Minden MD, Galarneau A and Pouliot JF: Phase II study of targeted therapy with temozolomide in acute myeloid leukaemia and high-risk myelodysplastic syndrome patients pre-screened for low $\mathrm{O}$ (6)-methylguanine DNA methyltransferase expression. Br J Haematol 167: 664-670, 2014.

11. Fasan A, Alpermann T, Haferlach C, Grossmann V, Roller A, Kohlmann A, Eder C, Kern W, Haferlach T and Schnittger S: Frequency and prognostic impact of CEBPA proximal, distal and core promoter methylation in normal karyotype AML: A study on 623 cases. PLoS One 8: e54365, 2013.

12. Chen C, Wang L, Liao Q, Huang Y, Ye H, Chen F, Xu L, Ye M and Duan S: Hypermethylation of EDNRB promoter contributes to the risk of colorectal cancer. Diagn Pathol 8: 199, 2013.

13. Vidal DO, Paixão VA, Brait M, Souto EX, Caballero OL, Lopes LF and Vettore AL: Aberrant methylation in pediatric myelodysplastic syndrome. Leuk Res 31: 175-181, 2007.

14. Reid T, Oronsky B, Scicinski J, Scribner CL, Knox SJ, Ning S, Peeh DM, Korn R, Stirn M, Carter CA, et al: Safety and activity of RRx-001 in patients with advanced cancer: A first-in-human, open-label, dose-escalation phase 1 study. Lancet Oncol 16: 1133-1142, 2015.

15. Malonia SK, Sinha S, Lakshminarasimhan P, Singh K, Jalota-Badhwar A, Rampalli S, Kaul-Ghanekar R and Chattopadhyay S: Gene regulation by SMAR1: Role in cellular homeostasis and cancer. Biochim Biophys Acta 1815: 1-12, 2011.

16. Johannes Z, Ina Radtke, Timothy S, Pardee, Zhen Zhao, Amy R, Rappaport,Weijun Luo, Mila E, McCurrach, Yang MM, Dolan ME, Kogan SC, et al: Mouse models of human AML accurately predict chemotherapy response. Genes Dev 23: 877-889, 2009.

17. Poddighe PJ, Wessels H, Merle P, Westers M, Bhola S, Loonen A, Zweegman S, Ossenkoppele GJ and Wondergem MJ: Genomic amplification of MYC as double minutes in a patient with APL-like leukemia. Mol Cytogenet 7: 67, 2014.

18. Ofran Y and Rowe JM: Acute myeloid leukemia in adolescents and young adults: Challenging aspects. Acta Haematol 132: 292-297, 2014.

19. Pui CH: Acute leukemias with the $\mathrm{t}(4 ; 11)(\mathrm{q} 21 ; \mathrm{q} 23)$. Leuk Lymphoma 7: 173-179, 1992.

20. Shahab F and Raziq F: Clinical presentations of acute leukemia. J Coll Physicians Surg Pak 24: 472-476, 2014. 